\title{
Comparison of the Modified Valsalva Maneuver and the Standard Valsalva Maneuver for Treatment of Supraventricular Tachycardia in Emergency Department
}

\author{
(1) Yahya Kemal Günaydın¹, (1) Fuat Koray Çelik ${ }^{2}$, (1) Sertaç Güler ${ }^{1}$, (1) Dilber Ucoz Kocasaban ${ }^{1}$ \\ ${ }^{1}$ Clinic of Emergency Medicine, University of Health Sciences Turkey, Ankara Training and Research Hospital, Ankara, Turkey \\ ${ }^{2}$ Clinic of Emergency Medicine, Amasya State Hospital, Amasya, Turkey
}

\begin{abstract}
Aim: The diagnosis and initial therapy of supraventricular tachycardia are always made in emergency departments. Vagal maneuvers are recommended as the first-line treatment for the termination of SVT. We aimed to compare the efficacy of standard and modified Valsalva maneuvers in treating patients with SVT.

Materials and Methods: This study was conducted between 16/03/2016 and 16/09/2016 at the Health Sciences University Ankara Training and Research Hospital Emergency Medicine Clinic. Our study was a randomized, prospective, case-control study. During the study, standard Valsalva maneuver (SVM) and modified Valsalva maneuver (MVM) were applied to two groups randomly allocated to patients with SVT. The maneuvering technique was determined by the envelope pulling method.

Results: This study was enrolled by 47 patients that included 23 patients who were treated by using SVM and 24 patients treated by using MVM. Four $(\% 17,4)$ people from the patients undergoing SVM returned to sinus rhythm, nine $(\% 37,5)$ people from the patients who underwent MVM returned to sinus rhythm. ( $p>0.05$ ) Although the results from the MVM treated patients were more satisfying, no statistically significant difference was detected.

Conclusion: In this study, we found that MVM is numerically superior in terms of success compared to SVM, but we could not prove this statistically. Therefore, we concluded that there was no difference between the two maneuvers in terms of success. In studies with more cases, we conclude that the result will be statistically significant.
\end{abstract}

Keywords: Supraventricular tachycardia, Vagal maneuvers, Modified Valsalva maneuver

\section{Introduction}

Supraventricular tachycardia (SVT); is a general term used for all tachycardias originating from the atrioventricular node. However, the term SVT is often used to describe sudden onset, regular, narrow complex tachycardias. Although the most common symptom is palpitation, it may present with chest pain, dizziness, and rarely fainting $(1,2)$. Vagal maneuvers are recommended as the first-line treatment for termination of SVT It is not invasive and does not require any medication. $(3,4)$. Valsalva maneuver performed in the supine position is the most effective vagal maneuver to terminate of SVT $(1,5,6)$. Although it is not a gold standard technique for Valsalva maneuver, in general, the patient exhales against the closed glottis to produce intrathoracic pressure equivalent to at least 30-40 mmHg for 10-30 seconds (6). In the modified Valsalva maneuver, 45 degrees elevation is applied to the feet of the patient for 15 seconds immediately after the normal Valsalva maneuver. Thus, it is aimed to increase venous return and vagal stimulation during relaxation phase $(7,8)$. In this study, we aimed to compare the efficacy of modified Valsalva maneuver and standard Valsalva maneuver on SVT patients and to evaluate the utility of modified Valsalva maneuver in the emergency department.

Cite this article as: Günaydın YK, Çelik FK, Güler S, Ucoz Kocasaban D. Comparison of the Modified Valsalva Maneuver and the Standard Valsalva Maneuver for Treatment of Supraventricular Tachycardia in Emergency Department. Eurasian J Emerg Med. 2021;20(2):230-5.

(C) Copyright 2021 by the Emergency Medicine Physicians' Association of Turkey

Eurasian Journal of Emergency Medicine published by Galenos Publishing House. 


\section{Materials and Methods}

This study was conducted between 16/03/2016 and 16/09/2016 at Ankara Training and Research Hospital Emergency Medicine Clinic, which had 350,000 emergency department patient applications annually. Our aim was to compare the efficacy of standard and modified Valsalva maneuvers in the treatment of patients with SVT. Our study was a randomized, prospective, case-control study. Permission was obtained from the training, planning and coordination committee and ethics committee of the same hospital. The study was conducted in accordance with the latest version of the Declaration of Helsinki and the Good Clinical Practices Directive.

\section{Sample Size}

When 81 cases were included in each group, 95\% power was provided with $5 \%$ error margin. However, we received 23 patients in the SVM group and 24 patients in the MVM group and provided $50 \%$ power with $5 \%$ error margin.

\section{Patient Selection}

Patients diagnosed as supraventricular tachycardia in the Emergency Medicine Clinic of Ankara Training and Research Hospital were included in the study. Written informed consent was obtained from the patients or their closest relatives. Patients under 18 years of age, hemodynamically unstable, GCS $<15$, chest pain at presentation, recent myocardial infarction, known aortic valve stenosis, and pregnant women were excluded. The number of cases included in the study was not limited. After completing the forms of the patients included in the study and completing their treatment, the data were checked. Patients with a lack of data or misdiagnosed patients were excluded from this study. After all these stages, 47 patients were analyzed statistically (Figure 1a).

\section{Electrocardiography Evaluation}

In these patients, 12-lead ECG is the most necessary and valuable test in the diagnosis. SVT diagnosis; The ECG is based on regular, narrow QRS complex (<120 msec) pulses with a rate of 160-200/ min, no $\mathrm{p}$ waves.

The Nihon Kohden ECG 1250 Cardiofax S (2009, Tokyo, Japan) device was used for recording ECGs. Records were obtained at $25 \mathrm{~mm} / \mathrm{s}$ speed and with $10 \mathrm{~mm} / \mathrm{mV}$ amplitudes. Prolonged QRS duration was defined as $\geq 120 \mathrm{~ms}$.

\section{Design of the Study}

During the study, standard Valsalva maneuver (SVM) and modified Valsalva maneuver (MVM) were applied to two groups randomly allocated to patients with SVT. The maneuvering technique was determined by envelope pulling method. For the study, a form was used to record demographic information, complaints, ECGs, vital signs, additional diseases and response to treatment options, and which maneuver would be performed. In the standard Valsalva maneuver; patients were asked to blow the 10 cc empty injector in a sitting position to push the plunger for 15 seconds and then return to normal respiration. In the modified Valsalva maneuver (MVM); The patients were asked to blow the 10 cc empty injector in a sitting position to push the plunger for 15 seconds. Immediately afterwards, the patient was passively taken to the supine position by the physician and the legs were elevated at an angle of 45 degrees for 15 seconds (Figure $1 b$ ). In unresponsive patients, both procedures were repeated 3 times at 1 minute intervals before switching to medical treatment according to the guidelines. $(6,7)$

\section{Statistical Analysis}

Data were analyzed in SPSS Windows 18 version. The distribution of the variables was checked by Kolmogorov-Simirnov test. Mean and standard deviation (SD) in descriptive statistics of parametric data; median and interquantile range (IQR) were used for descriptive statistics of non parametric data. Student's t-test was used for the analysis of quantitative parametric data and Mann Whitney $\mathrm{U}$ test was used for the analysis of the nonparametric data. The qualitative data were analyzed by pearson chi-square and Fisher's exact tests. $p<0.05$ was considered statistically significant.

\section{Results}

A total of 47 patients were included in the study. SVM was performed in 23 patients and MVM in 24 patients. The relationship between the type of maneuver and age was found to be statistically insignificant. The same conclusion applies to gender. There were no differences in age between the groups

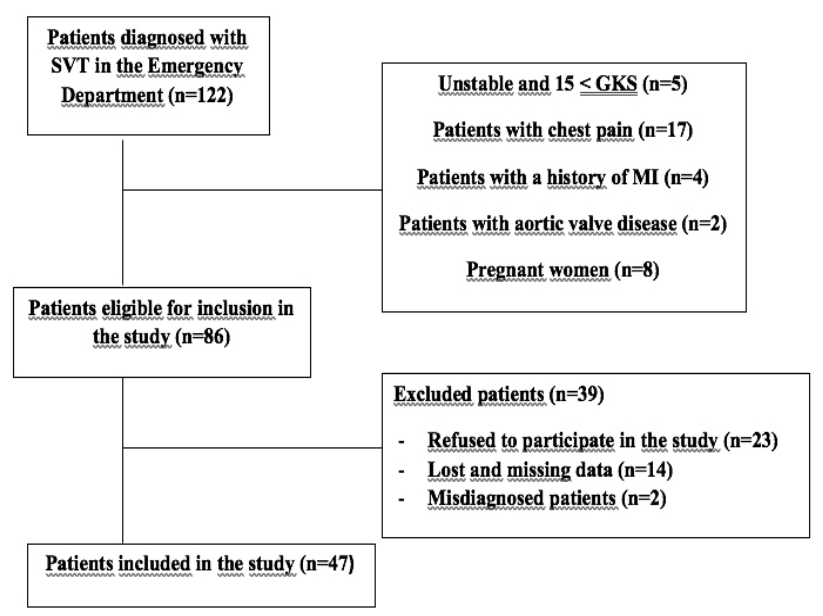

Figure 1a. Patient selection 


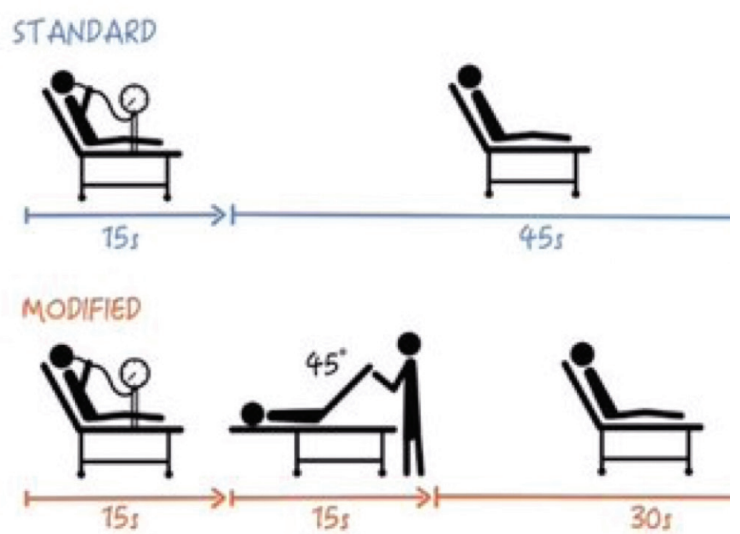

Figure 1b. Standard and modified Valsalva maneuvers are described in detail with the aid of a picture. The picture retrieved from: medmastery.com/magazine/modified-valsalva-maneuvervideo-review $(p>0.05)$. There was no gender difference between the groups $(p>0.05)$ (Table 1). There was no difference between the groups in terms of comorbidities. There was no difference between the groups in terms of vital parameters $(\mathrm{p}>0.05)$ (Table 2).

While $13(27.7 \%)$ patients had a response to Valsalva maneuver, $34(72.3 \%)$ had no response. While $4(17.4 \%)$ of the patients with SVM returned to sinus rhythm, 19 (82.6\%) remained in the SVT. While 9 (37.5\%) of the patients undergoing MVM returned to sinus rhythm, 15 (62.5\%) remained in SVT. Although the response of MVM patients was higher, there was no statistically significant difference $(p>0.05)$ (Table 3). Of the four patients who responded to SVM, three (75\%) responded in the first attempt and one $(25 \%)$ responded in the second attempt; Eight (88.9\%) out of nine patients who responded to MVM responded to the first attempt and one (11.1\%) responded to the third attempt. There was no statistically significant relationship between maneuver responsiveness and number of maneuvers ( $p>0.05$ ) (Table 3).

\begin{tabular}{|c|c|c|c|c|c|}
\hline & & $\begin{array}{l}\text { Total }(n=47) \\
\text { Mean } \pm \text { SD }\end{array}$ & $\begin{array}{l}\text { SVM }(n=23) \\
\text { Mean } \pm \text { SD }\end{array}$ & $\begin{array}{l}\text { MVM }(n=24) \\
\text { Mean } \pm \text { SD }\end{array}$ & p-value \\
\hline \multicolumn{2}{|l|}{ Age } & $48 \pm 15$ & $47.2 \pm 16.4$ & $48.8 \pm 14.0$ & 0.731 \\
\hline \multirow{2}{*}{ Gender } & Male & $19(40.4 \%)$ & $10(43.5 \%)$ & $9(37.5 \%)$ & \multirow{2}{*}{0.676} \\
\hline & Female & $28(59.6 \%)$ & $13(56.5 \%)$ & $15(62.5 \%)$ & \\
\hline
\end{tabular}

\begin{tabular}{|c|c|c|c|c|}
\hline & $\begin{array}{l}\text { Total }(n=47) \\
\text { Mean } \pm \text { SD }\end{array}$ & $\begin{array}{l}\text { SVM }(n=23) \\
\text { Mean } \pm \text { SD }\end{array}$ & $\begin{array}{l}\text { MVM }(n=24) \\
\text { Mean } \pm \text { SD }\end{array}$ & $p$-value \\
\hline SBP & $125.1 \pm 22.5$ & $129.2 \pm 25$ & $121.2 \pm 19.4$ & 0.224 \\
\hline DBP & $73.4 \pm 18.0$ & $73.1 \pm 22$ & $73.8 \pm 13.3$ & 0.901 \\
\hline Pulse & $174.4 \pm 19.3$ & $176.6 \pm 20.6$ & $172.3 \pm 18.1$ & 0.449 \\
\hline Fever & $36.7 \pm 0.4$ & $36.6 \pm 0.4$ & $36.7 \pm 0.4$ & 0.682 \\
\hline Respiratory rate & $17.2 \pm 3.6$ & $17.0 \pm 3.5$ & $17.4 \pm 3.9$ & 0.698 \\
\hline Saturation & $96.4 \pm 2.5$ & $95.9 \pm 2.8$ & $97.0 \pm 2.0$ & 0.164 \\
\hline \multicolumn{5}{|c|}{ Student t-test, SBP: Systolic blood pressure, DBP: Diastolic blood pressure, SVM: Standard valsalva maneuver, MVM: Modified valsalva maneuver } \\
\hline & $\begin{array}{l}\text { Total } \\
\mathrm{n}(\%)\end{array}$ & $\begin{array}{l}\text { SVM }(n=23) \\
n(\%)\end{array}$ & $\begin{array}{l}\text { MVM }(n=24) \\
n(\%)\end{array}$ & $p$-value \\
\hline HT & $13(27.7)$ & $5(21.7)$ & $8(33.3)$ & $0.374^{*}$ \\
\hline CAD & $11(23.4)$ & $3(13.0)$ & $8(33.3)$ & $0.101^{*}$ \\
\hline DM & $7(14.9)$ & $2(8.7)$ & $5(20.8)$ & $0.416^{* *}$ \\
\hline Asthma & $2(4.3)$ & $1(4.3)$ & $1(4.2)$ & $>0.999 * *$ \\
\hline COPD & $1(2.1)$ & 0 & $1(4.2)$ & $>0.999 * *$ \\
\hline CRF & $1(2.1)$ & $1(4.3)$ & 0 & $>0.489 * *$ \\
\hline
\end{tabular}

*Pearson chi square, **Fisher's Exact Test, HT: Hypertension, CAD: Coronary artery disease, DM: Diabetes mellitus, CRF: Chronic renal failure, COPD: Chronic obstructive pulmonary disease, SVM: Standard Valsalva maneuver, MVM: Modified Valsalva maneuver 
When the side effects developed in the study patients were evaluated, side effects (nausea) developed in one (7.7\%) of 13 patients who responded to Valsalva maneuver, while no side effects occurred in 12 (92.3\%). ( $p>0.05$ ) In our study, none of the four patients responding to SVM developed side effects; one (11.1\%) responding to MVM developed side effects (nausea) $(p>0.05)$ (Table 4).

\section{Discussion}

In different studies, the effectiveness of Valsalva maneuver was reported to be between 5\%-20\%. $(9,10)$ Different methods for Valsalva maneuver have been described; It was stated that pressure duration, applied pressure and patient position may change Valsalva efficacy $(9,11-19)$. Since 1988 , it is thought that by modifying the SVM by raising the legs, it will be easier to convert SVT to sinus rhythm. (20) In addition to SVM, epigastirum pressure or foot lifting may increase passive vagal stimulation by increasing venous return $(11,19)$. Cochrane analysis evaluated the efficacy of the Valsalva maneuver and indicated that the success of the procedure ranged from $19.4 \%$ to $54.3 \%$ with modifications. However, the level of evidence for this study was reported to be low (21). Wong et al. (11) in their studies with the lifting of the feet R-R distance is the longest, increased when the patient begins to erect and stated that the shortest sitting position. In this study, it was stated that posture on the back did not lead to changes in blood flow, leading to bradycardia (11). This hypothesis coincides with the results of Singer et al. (22) In their study by Walker and Cutting, patients were placed in the trelenderburg position and blown into a manometer to produce $40 \mathrm{mmHg}$ pressure for 15 seconds. They stated that the success rate of Valsalva maneuver increased to 31\% with this application (15). Wallentin and Sjol (23) reported that MVM was successfully applied without side effects in the case presented. $\mathrm{n}$ a case series published by Un et al. (24), MVM was applied to 5 patients who did not respond to standard vagal maneuvers. The patients were quickly taken from the sitting position to the supine position and were told to breathe deeply and slowly. The result was a return to sinus rhythm. This was attributed to increased venous return and increased baroreceptor activity triggering vagal stimulation. (24)

The first scientific randomized study was conducted by Appleboam et al. In 214 patients with SVM, 17\% success was achieved and in 214 patients with MVM, 43\% success was achieved. In the study, it was stated that MVM was superior (7). Michaud et al. (25) and Smith et al. (26) argued that Appleboam et al. (7) reported that MVM was superior to SVM. In our study, the response to SVM was $17.4 \%$ and the response to MVM was $37.5 \%$, and this difference

Table 3. Comparison of responses to SVM versus MVM. The relationship between the maneuver response and the number of maneuvering

\begin{tabular}{|c|c|c|c|c|c|}
\hline & & Total & $\operatorname{SVM}(n=23)$ & $\operatorname{MVM}(n=24)$ & p-value \\
\hline \multirow{2}{*}{ Response } & Yes & $13(27.7 \%)$ & $4(17.4 \%)$ & $9(37.5 \%)$ & \multirow{2}{*}{0.123} \\
\hline & No & $34(72.3 \%)$ & $19(82.6 \%)$ & $15(62.5 \%)$ & \\
\hline & & Number & SVM $(n=4)(\%)$ & $\operatorname{MVM}(n=9)(\%)$ & p-value \\
\hline \multirow{3}{*}{\multicolumn{2}{|c|}{ Number of maneuvers }} & 1 & $3(75)$ & $8(88.9)$ & \multirow{3}{*}{$s>0.999$} \\
\hline & & 2 & $1(25)$ & 0 & \\
\hline & & 3 & 0 & $1(11.1)$ & \\
\hline
\end{tabular}

Table 4. Comparison of response to Valsalva maneuver and side effects

\begin{tabular}{|c|c|c|c|}
\hline \multirow[b]{2}{*}{ Side effect } & \multicolumn{2}{|c|}{ Response to Valsalva maneuver } & \multirow[b]{2}{*}{ p-value } \\
\hline & $\begin{array}{l}\text { Yes }(n=13) \\
n(\%)\end{array}$ & $\begin{array}{l}\text { No }(n=34) \\
n(\%)\end{array}$ & \\
\hline Yes & $1(7.7)$ & $9(26.5)$ & \multirow{2}{*}{0.244} \\
\hline No & $12(92.3)$ & $25(73.5)$ & \\
\hline Side effect & $\begin{array}{l}\text { SVM }(n=4) \\
n(\%)\end{array}$ & $\begin{array}{l}\operatorname{MVM}(n=9) \\
n(\%)\end{array}$ & p-value \\
\hline Yes & 0 & $1(11.1)$ & \multirow{2}{*}{$>0.999$} \\
\hline No & $4(100)$ & $8(88.9)$ & \\
\hline
\end{tabular}


was not statistically significant. Our treatment response rate was consistent with the study of Appleboam et al. However, it contradicts statistical significance. We believe that MVM is a more effective method. However, the reason for the lack of statistical significance is attributed to the small number of cases. We think that the elevation of the leg in MVM increases the venous return to the heart more and causes a better vagal response.

There was no relationship between the frequency of Valsalva maneuver application and response to maneuver in the literature. Appelboam et al. (7) stated that the results determined for SVM and MVM belong to the first minute, and that the response time was similar (7). In our study, $84.6 \%$ of the cases responded to Valsalva maneuver at the first application. The frequency of response of SVM and MVM in the first application was similar. Appelboam et al. (7) reported that none of the patients undergoing SVM and MVM had any serious side effects. Non-serious side effects such as hypotension, dizziness, nausea and musculoskeletal pain have been reported (7). Walker and Cutting reported that MVM is generally well tolerated, vomiting develops in only one patient and is superior to adenosine in terms of side effects (16). In our study, one of the patients who had MVM developed side effects and there was no difference between side effects and type of maneuver.

\section{Conclusion}

In this study, we found that MVM is numerically superior in terms of success compared to SVM, but we could not prove this statistically. Therefore, we concluded that there was no difference between the two maneuvers in terms of success. We think that this is due to the small number of cases included in the study. In studies with more cases, we conclude that the result will be statistically significant. We anticipate that MVM can be used safely in emergency departments due to the absence of serious side effects in the treatment protocol applied, no difference in terms of serious side effects compared to SVM, and the ease of treatment.

\section{Study Limitations}

When the literature is examined, studies on the subject are limited. In general, studies involving a small number of cases have been performed. Likewise, in our study, we reached a small number of cases in parallel with the literature. The reason for this is that our study is single-centered and performed within a certain period of time. Therefore, we think that the use of MVM in emergency services will become widespread with the increasing number of studies involving many patients. Thus, in the treatment of SVT, emergency physicians will be provided with a treatment alternative that is easier to do and with less side effects.

\section{Ethics}

Ethics Committee Approval: This study was approved by Ankara Training and Research Hospital (decision no: 5319-633, date: 16/03/2016).

Informed Consent: Written informed consent was obtained from the patients or their closest relatives.

Peer-review: Externally peer-reviewed.

\section{Authorship Contributions}

Surgical and Medical Practices: F.K.C., S.G., Y.K.G., Concept: F.K.Ç., S.G., Y.K.G., Design: F.K.C., S.G., Y.K.G., Data Collection or Processing: F.K.C.., S.G., D.U.K., Analysis or Interpretation: Y.K.G., D.U.K., Literature Search: F.K.C.., Y.K.G., D.U.K. Writing: F.K.C.., Y.K.G.

Conflict of Interest: No conflict of interest was declared by the authors.

Financial Disclosure: The authors declared that this study received no financial support.

\section{References}

1. William J. Brady, Thomas S. Laughrey, and Chris A. Ghaemmaghami. Cardiac Rhythm Disturbances. Tintinalli's Emergency Medicine A Comprehensive Study Guide 8th edition McGraw-Hill, New York, 2016.

2. Rosen's Emergency Medicine-Concepts and Clinical Practice 8th Edition Chapter 79, Elsevier, Amsterdam, 2013.

3. Page RL, et al. 2015 ACC/AHA/HRS SVT Guideline: Executive Summary.

4. Ganz LI, Friedman PL. Supraventricular tachycardia. N Engl 」 Med. 1995;332:162-73

5. Wen ZC, Chen SA, Tai CT, Chiang CE, Chiou CW, Chang MS. Electrophysiological mechanisms and determinants of vagal maneuvers for termination of paroxysmal supraventricular tachycardia. Circulation. 1998;98:2716-23.

6. Page RL, Joglar JA, Caldwell MA, Calkins H, Conti JB, Deal BJ, et al. 2015ACC/AHA/ HRS guideline for the management of adult patients with supraventricular tachycardia: A Report of the American College of Cardiology/American Heart Association Task Force on Clinical Practice Guidelines and the Heart Rhythm Society. Heart Rhythm. 2016;13:e136-221.

7. Appelboam A, Reuben A, Mann C, Gagg J, Ewings P, Barton A, et al. Postural modification to the standard Valsalva manoeuvre for emergency treatment of supraventricular tachycardias (REVERT): a randomised controlled trial. Lancet. 2015;386:1747-53

8. Fox DJ, Tischenko A, Krahn AD, Skanes AC, Gula LJ, Yee RK, et al Supraventricular tachycardia: diagnosis and management. Mayo Clin Proc. 2008:83:1400-11.

9. Smith G, Morgans A, Boyle M. Use of the Valsalva manoeuvre in the prehospital setting: a review of the literature. Emerg Med J. 2009;26:8-10.

10. Lim SH, Anantharaman V, Teo WS, Goh PP, Tan AT. Comparison of treatment of supraventricular tachycardia by Valsalva maneuver and carotid sinus massage. Ann Emerg Med. 1998;31:30-5.

11. Wong LF, Taylor DM, Bailey M. Vagal response varies with Valsalva maneuver technique: a repeated-measures clinical trial in healthy subjects. Ann Emerg Med. 2004:43:477-82.

12. Advanced Life Support Group. Advanced paediatric life support: the practical approach. 4th edn. UK: Blackwell Publishing Group, 2005. 
13. Resuscitation Council (UK). Resuscitation Guidelines. http://www.resus.org. uk/pages/guide.htm; 2010.

14. Wyatt JP, Illingworth RN, Clancy MJ, et al. Oxford handbook of accident \& emergency medicine. Oxford University Press, Oxford, 2000.

15. Walker S, Cutting P. Impact of a modified Valsalva manoeuvre in the termination of paroxysmal supraventricular tachycardia. Emerg Med J. 2010;27:287-91.

16. Çetiner M, Göldeli Ö, Kulan K, Komşuoğlu B. Valsalva manevrası. Türk Kardiyol Dern Arș 1993;21:251-7.

17. Chance JF, Warner JG, Elsawy T. Augmented Valsalva maneuver for supraventricular tachycardia in the young. Ann Intern Med. 1992;116:523.

18. Torren A. Modified Valsalva maneuver for paroxysmal supraventricular tachycardia. Cardiovasc Drugs Ther. 1997;11:91.

19. Appelboam A, Gagg J, Reuben A. Modified Valsalva manoeuvre to treat recurrent supraventricular tachycardia: description of the technique and its successful use in a patient with a previous near fatal complication of DC cardioversion. BMJ Case Rep. 2014;2014:bcr2013202699.

20. Mehta D, Wafa S, Ward DE, Camm AJ. Relative efficacy of various physical manoeuvres in the termination of junctional tachycardia. Lancet. 1988;1:1181-5.
21. Smith GD, Dyson K, Taylor D, Morgans A, Cantwell K. Effectiveness of the Valsalva Manoeuvre for reversion of supraventricular tachycardia. Cochrane Database Syst Rev. 2013;(3):CD009502.

22. Singer W, OpferGgehrking TL, McPhee BR, Hilz MJ, Low PA. Influence of posture on the Valsalva manoeuvre. Clin Sci (Lond). 2001;100:433-40.

23. Wallentin J, Sjøl A. Vellykket behandling af supraventrikulær takykardi med modificeret Valsalvas manøvre [Successful treatment of supraventricular tachycardia with a modified Valsalva manoeuvre]. Ugeskr Laeger. 2016;178:V12150998.

24. Un H, Dogan M, Uz O, Isilak Z, Uzun M. Novel vagal maneuver technique for termination of supraventricular tachycardias. Am J Emerg Med. 2016;34:118. e5-7.

25. Michaud A, Lang E. Leg Lift Valsalva Maneuver for Treatment of Supraventricular Tachycardias. CJEM. 2017;19:235-7.

26. Smith GD. A modified Valsalva manoeuvre results in greater termination of supraventricular tachycardia than standard Valsalva manoeuvre. Evid Based Med. 2016;21:61. 